Case Report

\title{
Recurrent Solitary Fibrous Tumor in Intradural Extramedullary Space: Case Report and Review of the Literature
}

\author{
Neris Dincer $\left(\mathbb{D},{ }^{1}\right.$ Melisa Bagci $\left(\mathbb{D},{ }^{1}\right.$ Metin Figen ${ }^{D},{ }^{1}$ Adem Yilmaz, ${ }^{2}$ \\ Ahmet Mesrur Halefoglu $\left(\mathbb{D}^{3},{ }^{3}\right.$ Canan Tanik $\left(\mathbb{0},{ }^{4}\right.$ and Esengul Kocak Uzel $\oplus^{1}$ \\ ${ }^{1}$ Department of Radiation Oncology, Şişli Etfal Teaching and Research Hospital, Istanbul, Turkey \\ ${ }^{2}$ Department of Neurosurgery, Şişli Etfal Teaching and Research Hospital, Istanbul, Turkey \\ ${ }^{3}$ Department of Radiology, Şişli Etfal Teaching and Research Hospital, Istanbul, Turkey \\ ${ }^{4}$ Department of Pathology, Şişli Etfal Teaching and Research Hospital, Istanbul, Turkey \\ Correspondence should be addressed to Esengul Kocak Uzel; dresengulkocak@gmail.com
}

Received 11 May 2021; Accepted 28 October 2021; Published 20 November 2021

Academic Editor: Ossama W. Tawfik

Copyright (C) 2021 Neris Dincer et al. This is an open access article distributed under the Creative Commons Attribution License, which permits unrestricted use, distribution, and reproduction in any medium, provided the original work is properly cited.

Solitary fibrous tumor/hemangiopericytoma (SFT/HPC) is a rare neoplasm arising from spindle cells and most commonly arising from pleura. Spinal SFT/HPC is a rare entity; hence, it is not on the top of the differential diagnosis list when a clinician faces a spinal lesion. In the review of the literature, there exist less than 50 case reports of intradural extramedullary SFT/HPC. Here, we present a 54-year-old female patient who underwent subtotal surgical excision of an intradural extramedullary spinal mass pathologically reported to be SFT/HPC and had symptomatic recurrence in the $3^{\text {rd }}$ year of follow-up. Surgical intervention was unachievable and the patient was given $45 \mathrm{~Gy}$ to the surgical cavity followed by a $5.4 \mathrm{~Gy}$ boost to visible tumor with external radiotherapy. Patient reported significant relief of her symptoms. We aim to contribute to the formation of a treatment algorithm for this rare entity.

\section{Introduction}

Solitary fibrous tumors (SFT) (formerly known as hemangiopericytoma (HPC)) are rare mesenchymal neoplasms originating from spindle cells [1]. Although the majority arise from pleura, $60 \%$ of SFTs originate outside the pleura [2], and SFTs are deemed to arise anywhere in the body. CD34 is a sensitive marker though it is not specific, and lately specific markers are identified [3]. Although surgery with negative margins is the mainstay treatment, the role of chemotherapy and radiotherapy is under debate [4]. This report presents a case of intradural extramedullary (IDEM) SFT in the thoracic spine.

\section{Case Report}

Our patient is a 54-year-old female with a past medical history including asthma and peptic ulcer disease. Her family history is free of malignant diseases. In 2016, patient's chest
X-ray examination found a suspicious lesion. Magnetic resonance imaging (MRI) was ordered for further investigation in November 2017 since the patient was complaining of back pain. MRI revealed a spinal lesion $12 \times 10 \mathrm{~mm}$ in diameter at the level of second thoracic vertebra (T2) (Figures 1(a) and 1(b)). The patient was referred to surgery and one month later underwent total laminectomy at the level of second thoracic vertebra (T2) and subtotal excision of intradural extramedullary lesion with neuromonitoring. The lesion involved nerve roots; complete resection could not be achieved due to perioperative neuromonitor signals. Postoperative neurological examination showed motor strengths as $3 / 5$ for the left thigh, $3 / 5$ for the left knee, $0 / 5$ for the left foot, and $4 / 5$ for the left hand. Patient was started on corticosteroid. Left lower extremity strength improved to $4 / 5$, and the patient was discharged on postoperative day 4. A follow-up physical examination and MRI examination were planned for the patient 45 days after the surgery. Pathology report confirmed a WHO 2016 Grade 1 solitary fibrous tumor positive 


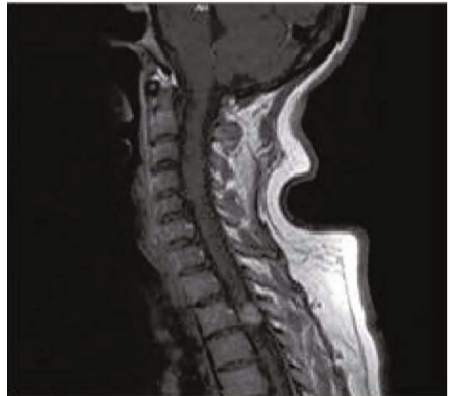

(a)

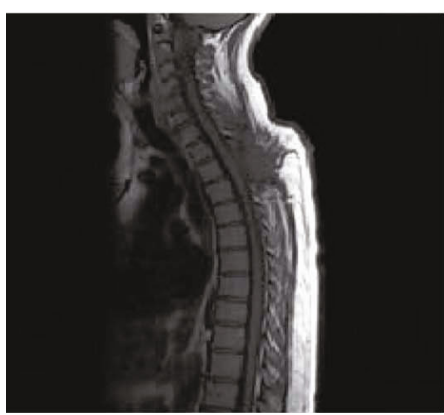

(c)

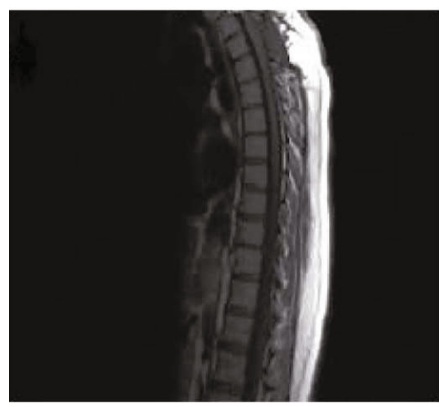

(e)

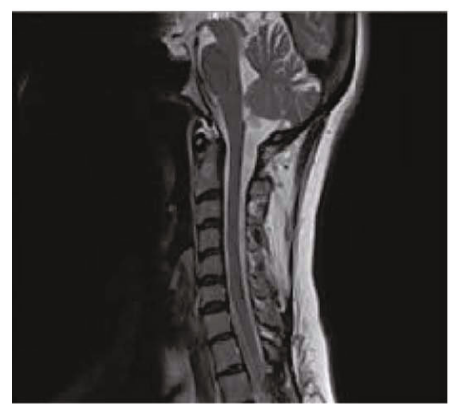

(g)

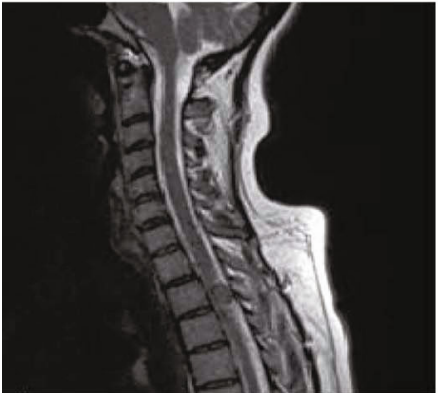

(b)

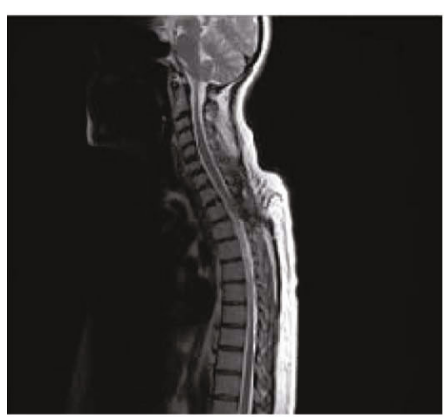

(d)

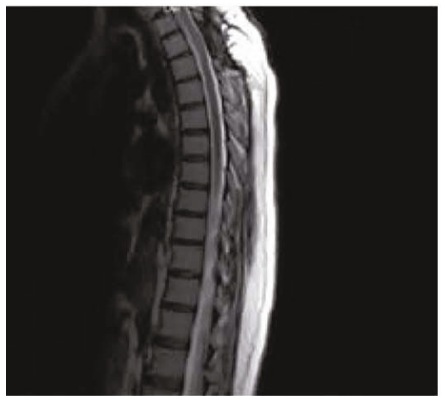

(f)

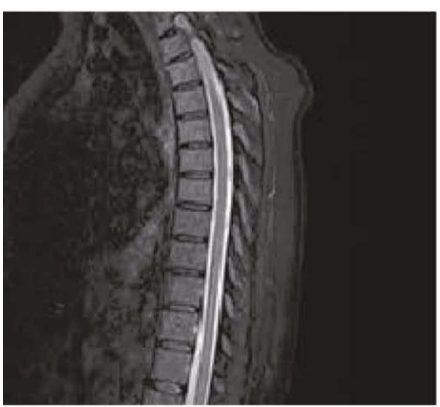

(h)

FIGURE 1: MRI images on preoperative, 3 months postoperative, 1 year postoperative, and current period. (a, b) (08.12.2017) Preoperative MRI reveals a lesion $12 \times 10 \mathrm{~mm}$ in diameter, hypointense in both T1-w and T2-w, heterogeneously contrast enhancing with gadolinium. (c, d) (06.03.2018) Postoperative MRI reveals a paracentral mass located in the posterior edge of the spinal canal with minimal contrast enhancement. (e, f) (19.01.2019) Control MRI reveals. (g, h) (18.02.2021): MRI at current presentation reveals a lesion which is moderately hypointense in T1-w and hypointense in T2-w with homogeneous contrast enhancement.

for CD34 and negative for S100, epithelial membrane antigen (EMA), and p53 (Figure 2). Thereafter, the patient underwent routine follow-up. MRI was performed 45 days after the surgery, and it was consistent with a remnant paracentral mass (Figures $1(\mathrm{c})$ and $1(\mathrm{~d})$ ). Control MRI a year after showed regression of the lesion (Figures 1(e) and $1(f)$ ). In June 2020, no intraspinal mass lesion was revealed on MRI. In January 2021, the patient came for routine follow-up with a complaint of bilateral pain in her upper extremities as well as back pain. MRI examination of the 


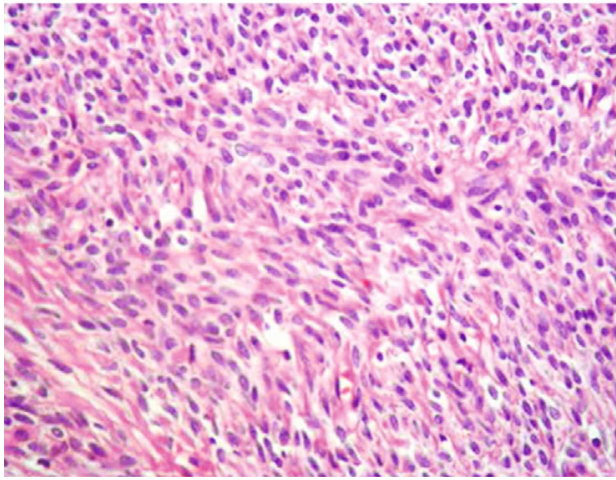

(a)

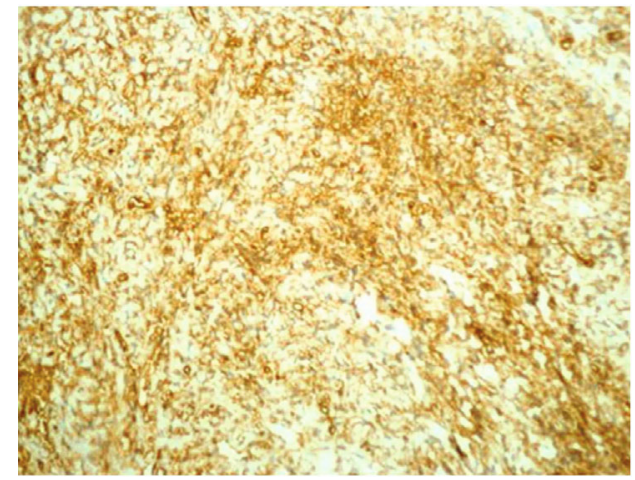

(b)

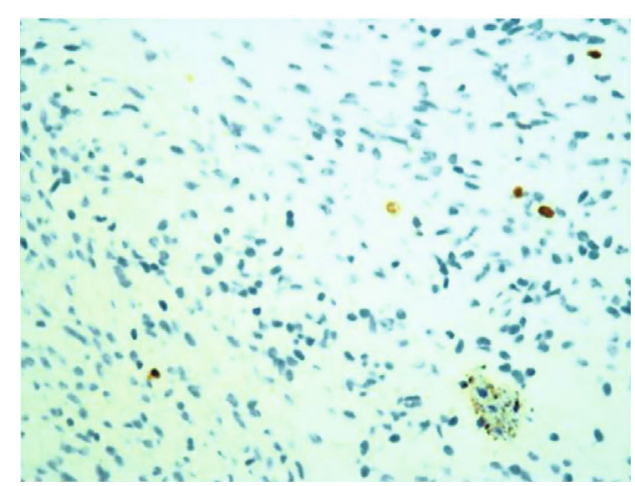

(c)

FIgUre 2: Pathology slides. (a) Hematoxylin and eosin staining of z200 magnification reveals spindloid nuclei and thin vascular structures. (b) Diffuse staining with CD34 at $\times 200$ magnification. (c) $1-2 \%$ proliferation index with Ki-67 at $\times 200$ magnification.

patient was consistent with an intradural extramedullary lesion $10 \times 5 \mathrm{~mm}$ in diameter which was compressing the spinal canal in the left paramedian area at the level of T2.

The patient was presented at the multidisciplinary tumor board for treatment options. Given the critical anatomic location and close involvement with nerve roots, the patient was found unsuitable for surgery. Eventually, the board decided on the referral to the radiation oncology clinic. A repeat contrasted thin-slice MRI of cervical and thoracic spine was performed (Figures $1(\mathrm{~g})$ and $1(\mathrm{~h})$ ). The report confirmed the recent findings. Patient underwent $1 \mathrm{~mm}$ thin slice treatment-planning computer tomography (CT) with intravenous contrast infusion. CT-MRI image fusion was acquired with the preoperative and present MRI for better discrimination of the resection cavity and the boundaries of the present lesion to achieve improved target delineation for treatment planning [5]. Gross tumor volume (GTV) was defined as the postoperative surgical cavity and clinical target volume (CTV) was extended $2 \mathrm{~cm}$ above and below the GTV. Planned RT dose was 45 Gray (Gy) in 25 fractions (1.8 Gy/fraction) and a boost of $5.4 \mathrm{~Gy}$ in 3 fractions ( $1.8 \mathrm{~Gy} /$ fraction). Organs at risk (OAR) were determined as the spinal cord, lungs, and esophagus in accordance with the atlas of dose constraints in thoracic radiotherapy published by Kong et al. [6]. Maximum point dose constraint to the spinal cord was determined to be 45 Gray (Gy) in accordance with the Quantitative Analyses of Normal Tissue Effects in the Clinic (QUANTEC) model to avoid any radiationrelated side effect, namely, myelopathy [7]. Treatment planning was done with conformal three-dimensional (3D), intensity-modified radiation therapy (IMRT), and volumetric modulated arc therapy (VMAT, hereinafter referred to as ARC) approach, respectively (Figure 3). QUANTEC normal tissue tolerances were taken into consideration and the calculations were made accordingly (Table 1) [8]. ARC was the chosen modality with optimal spinal cord protection compared to $3 \mathrm{D}$ and tolerable treatment duration for patient comfort and cooperation to stand immobile during the treatment compared to IMRT.

\section{Discussion}

Primary spinal cord tumors are rare neoplasms that constitute $4.5 \%$ of central nervous system (CNS) tumors in adults [9]. Their primary treatment is surgical resection if possible [10], and radiotherapy can ensue if total resection is not achieved [11]. They are classified according to their location as extradural, intradural extramedullary and intramedullary. Extradural tumors are most common followed by intradural extramedullary (IDEM) tumors. Meningioma, schwannoma, and neurofibroma comprise the majority of intradural extramedullary tumors [12]. Solitary fibrous tumors of intradural extramedullary space is a rare entity. They correspond to the 

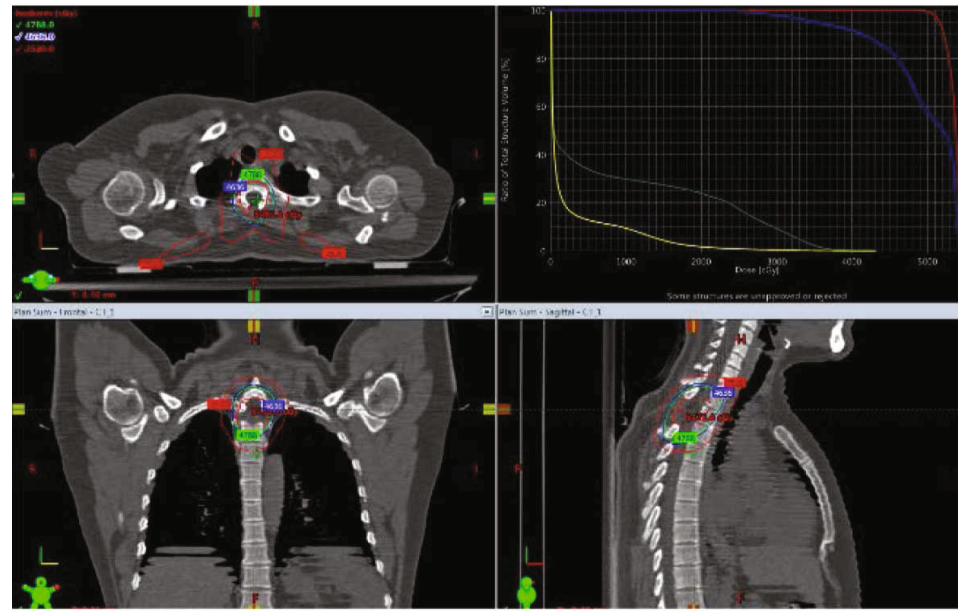

(a)

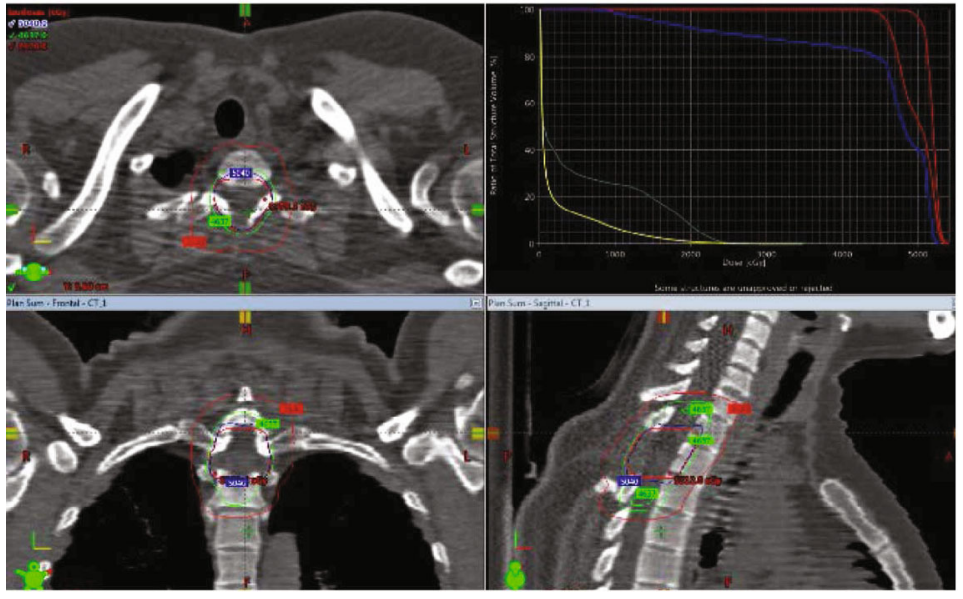

(b)
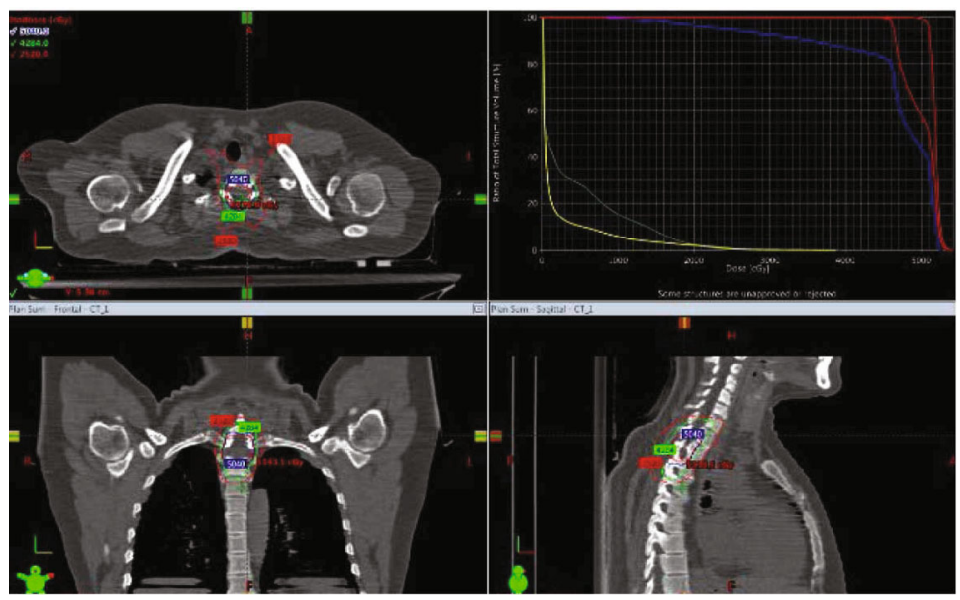

(c)

FIgURE 3: Plan summations and dose volume histogram (DVH) of 3DCRT, IMRT, and ARC. (a) Plan summations on axial (upper left), frontal (lower left), and sagittal (lower right) views and DVH graph (upper right) of conformal three-dimensional plan. Outer red line of plan summations represents 50\% (25.2 Gy) isodose line, green line represents $42.84 \mathrm{~Gy}$, and blue line represents $50.4 \mathrm{~Gy}$. Red dots represent maximum point doses on each view. (b) Plan summations on axial (upper left), frontal (lower left), and sagittal (lower right) views and DVH graph (upper right) of intensity-modulated radiation therapy plan. Outer red line of plan summations represents $50 \%$ $(25.2 \mathrm{~Gy})$ isodose line, green line represents $42.84 \mathrm{~Gy}$, and blue line represents $50.4 \mathrm{~Gy}$. Red dots represent maximum point doses on each view. (c) Plan summations on axial (upper left), frontal (lower left), and sagittal (lower right) views and DVH graph (upper right) of volumetric modulated arc therapy plan. Outer red line of plan summations represents $50 \%$ (25.2 Gy) isodose line, green line represents $42.84 \mathrm{~Gy}$, and blue line represents $50.4 \mathrm{~Gy}$. Red dots represent maximum point doses on each view. 
TABLE 1: Comparison of treatment plans.

\begin{tabular}{|c|c|c|c|c|c|c|c|c|c|c|}
\hline & \multirow[b]{2}{*}{$\begin{array}{l}\mathrm{D} 50 \\
(\mathrm{cGy})\end{array}$} & \multirow{2}{*}{$\begin{array}{l}\text { PTV } \\
\text { D98 } \\
\text { (cGy) }\end{array}$} & \multirow[b]{2}{*}{$\begin{array}{c}\mathrm{D} 2 \\
(\mathrm{cGy})\end{array}$} & \multirow{2}{*}{$\begin{array}{c}\text { Spinal } \\
\text { cord } \\
\text { D2 (cGy) }\end{array}$} & \multicolumn{3}{|c|}{ Lung } & \multicolumn{2}{|c|}{ Esophagus } & \multirow{2}{*}{$\begin{array}{l}\text { Monitor unit } \\
\text { (MU) }\end{array}$} \\
\hline & & & & & $\begin{array}{l}\text { V20 } \\
(\%)\end{array}$ & $\begin{array}{l}\text { V5 } \\
(\%) \\
\end{array}$ & $\begin{array}{l}\text { Mean } \\
(\mathrm{cGy})\end{array}$ & $\begin{array}{c}33 \% \\
(\mathrm{cGy}) \\
\end{array}$ & $\begin{array}{l}\text { Mean } \\
(\mathrm{cGy})\end{array}$ & \\
\hline $3 \mathrm{D}$ & 5370 & 5090 & 5468 & 5437 & 1.7 & 12.5 & 230 & 839 & 562 & 455 \\
\hline $\begin{array}{l}\text { IMRT ( } 5 \\
\text { field) }\end{array}$ & 5182 & 5067 & 5302 & 5226 & 2 & 10 & 190 & 385 & 255 & 1353 \\
\hline ARC & 5200 & 4950 & 5333 & 5220 & 1 & 12 & 207 & 540 & 326 & 1060 \\
\hline
\end{tabular}

3D: conformal three-dimensional; IMRT: intensity-modified radiation therapy; ARC: volumetric modulated arc therapy; PTV: planning target volume; D95: dose covering 95\% of the PTV; D50: median dose, D98: near-minimum dose, D2: near-maximum dose; cGy: centigray; V20: lung volume that received a dose of $20 \mathrm{~Gy}$ or more; V5: lung volume that received a dose of $5 \mathrm{~Gy}$ or more; 33\%: dose received by $33 \%$ of esophagus.

TABLE 2: Liu classification for localization of spinal SFTs [13].

\begin{tabular}{lr}
\hline Type & Subtype \\
\hline Type 1: extradural & IA, intracanal type \\
Type II: intradural & IB, intra- and extracanal type \\
Type III: intra- to extradural and paravertebral type & IIA, extramedullary type \\
\hline
\end{tabular}

group IIA in the classification of Liu et al. [13] (Table 2). The majority of type IIA spinal SFTs arise at the thoracic spine [12]. Table 3 summarizes the cases present in the PUBMED database.

Due to their rareness, SFTs are not on the top of the differential diagnoses list when the clinician is faced with a lesion in the spinal cord [14]. MRI is the preferred modality to delineate the tumor and evaluate for invasion, but the imaging findings are variable and nonspecific [15]. Nevertheless, the diagnosis is less of a challenge with the advances in knowledge in pathological markers. CD34, although not specific, is deemed to be the histological hallmark of SFTs and has been found to be expressed in $79 \%$ of cases [16, 17]. A retrospective study with 16 SFTs located in the spinal cord confirmed this finding with $100 \%$ SFTs being positive for CD34 and negative for EMA, GFAP, and MBP staining. S-100 positivity varied with 5 of the patients staining positive [18]. Lately, STAT6 and GRIA2 are proposed to be distinguishing markers for SFTs $[19,20]$. STAT6 expression is driven by NAB2STAT6 gene fusion, and STAT6 has lately been sought to be a specific marker for SFT [19, 21, 22]. STAT6 positivity in SFTs and HPCs is considered as finding that supports the abolishment of the thin boundary between these 2 entities in late 1990s [3, 23, 24].

Achieving complete surgical resection is the main goal in extrathoracic SFTs, and it is associated with improved local control and survival. Routine long-term follow-ups must be ensured for the early detection of recurrence [25]. Although there are no standardized follow-up routines for these patients. The anatomical location of the tumor may not allow the total resection in some cases [4]. The role of radiotherapy is under debate in SFTs.
There are studies advocating that RT is not strictly indicated after complete resection due to close follow-up and low recurrence rate [4] and that adjuvant radiotherapy can be considered in the case of subtotal resection [26-28] or if we are facing a high grade SFT [29]. There are studies advocating adjuvant radiotherapy be standard of treatment [18, 30]. Complete resection, low-grade tumor and young age were reported to be factors that led the clinicians to omit radiotherapy [31]. Krengli et al. revised 151 extrathoracic SFT patients while Wang et al. reviewed 16 spinal SFT patients in terms of the effect of GTR vs. GTR+RT on local recurrence (LC), disease-free survival (DFS), and overall survival (OS), and they both came up with the same conclusion: addition of adjuvant RT improved LS and DFS while GTR was the main predictor of OS $[18,32]$. While a retrospective review reveals that the median radiation dose for extracranial SFTs is $60 \mathrm{~Gy}$ [32], this dose seems to be unachievable in the spinal SFTs due to dose constraints of the spinal cord, which is $45-50 \mathrm{~Gy}$. Retrospective single center study of Wang et al. reported a median dose of $40 \mathrm{~Gy}$ in patients with spinal SFT [18]. The treatment plan must be tailored according to location and extent of the tumor. Radiation doses may vary in between patients if the plan cannot limit spinal cord doses in the desired limits.

Herein, we present a case of IDEM SFT who had STR 27 months prior to presentation to our clinic with bilateral pain over the arms and legs and newly developed radiological evidence of recurrence. Radiotherapy was the treatment of choice for this patient due to the location of the tumor. To our knowledge, we present the $5^{\text {th }}$ case of a recurrent SFT treated with radiotherapy [18, 33-35]. 


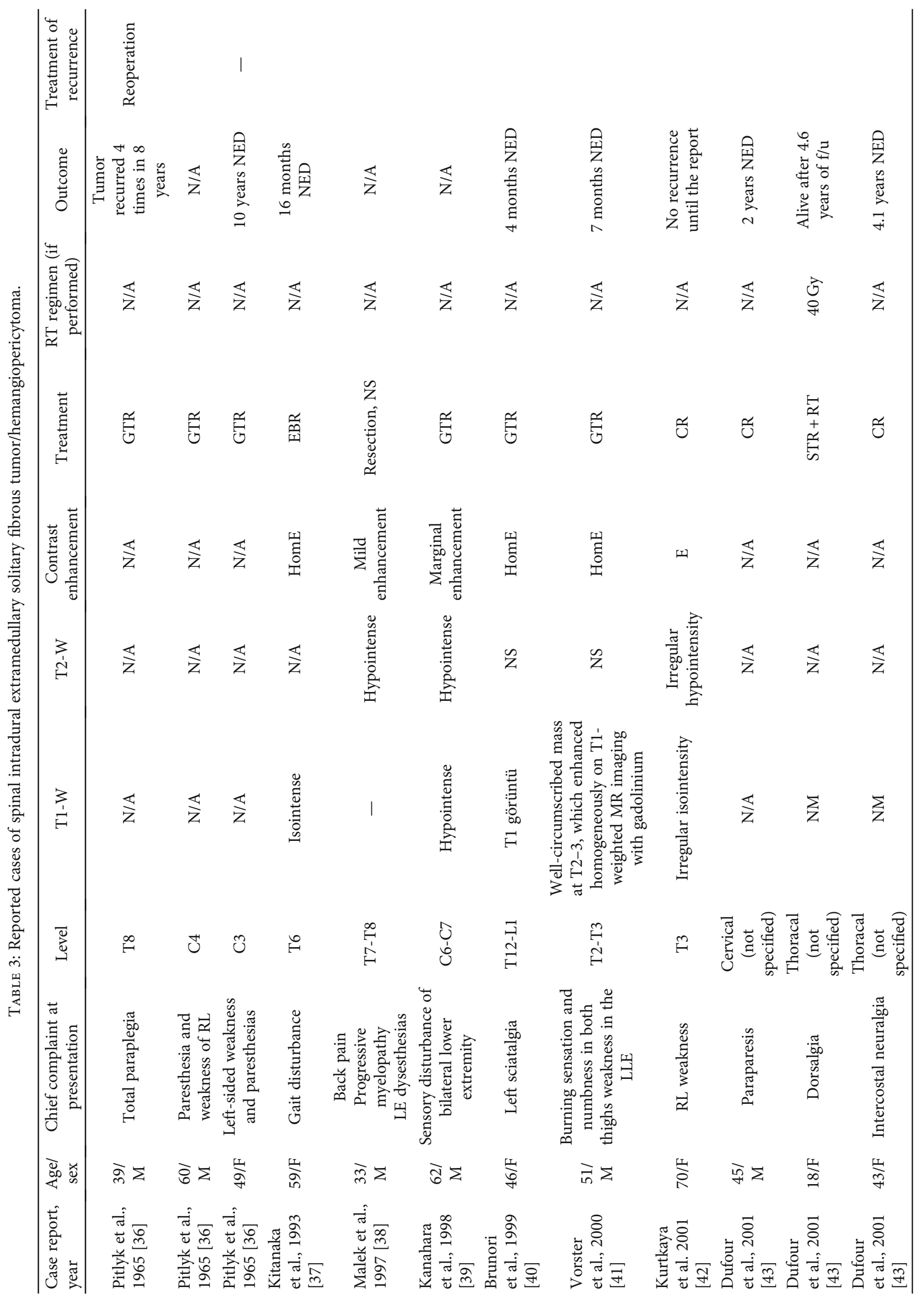




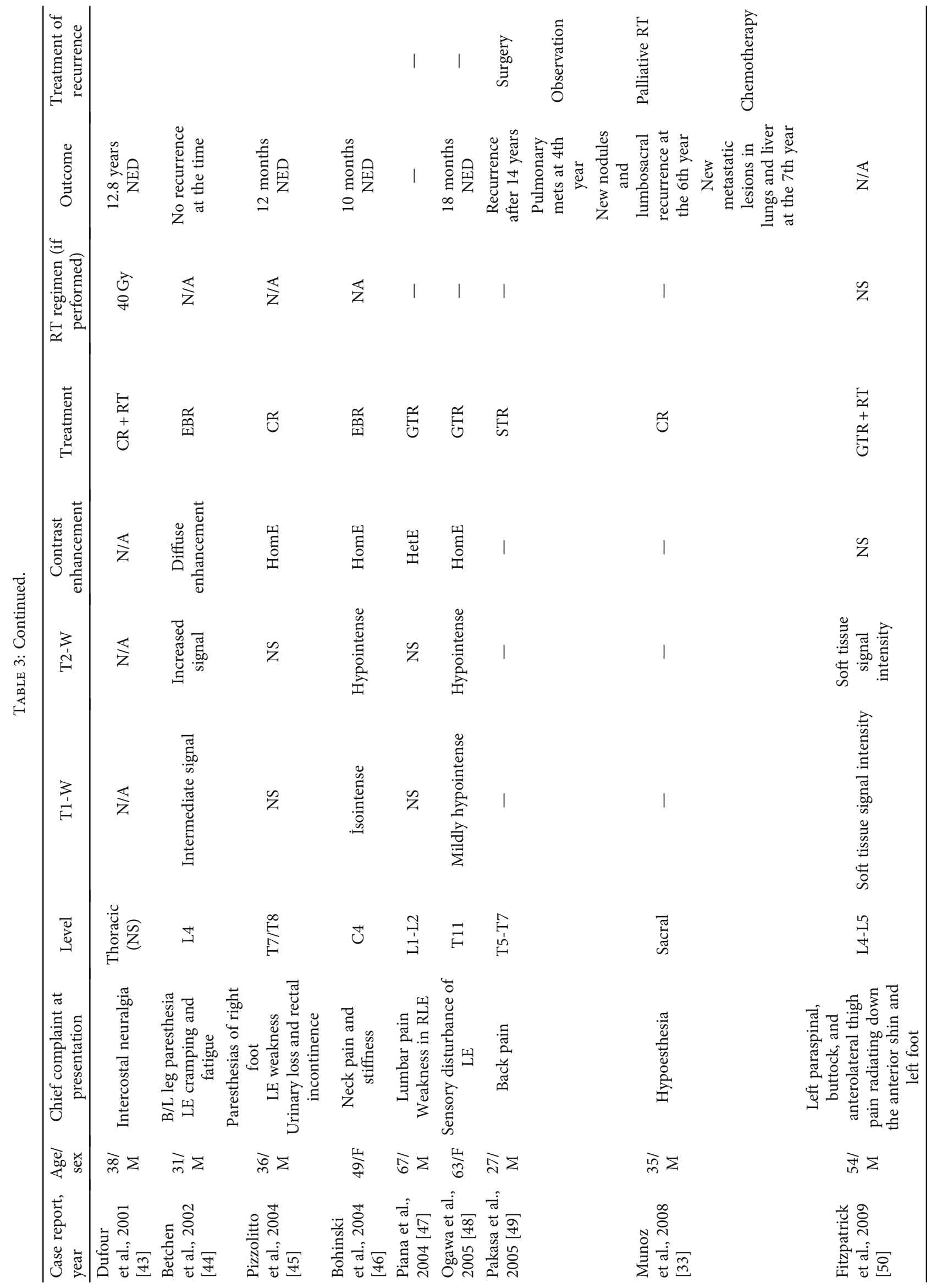




\begin{tabular}{|c|c|c|c|c|c|c|c|c|c|c|}
\hline 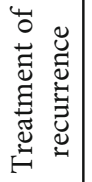 & & & & 1 & I & & & 乙䓒 & & \\
\hline 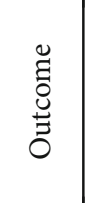 & 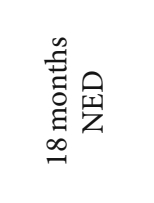 & 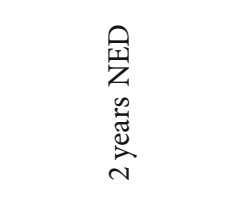 & $\overleftrightarrow{\Xi}$ & 1 & 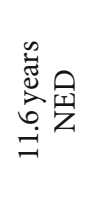 & 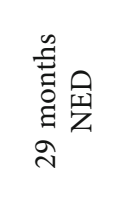 & 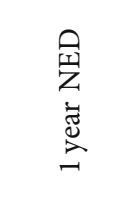 & 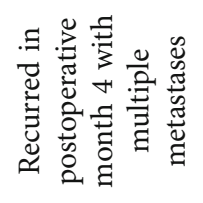 & 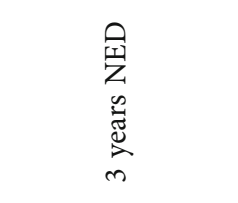 & 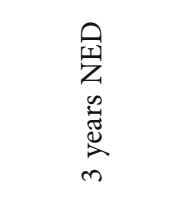 \\
\hline 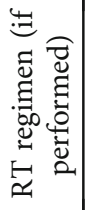 & 1 & 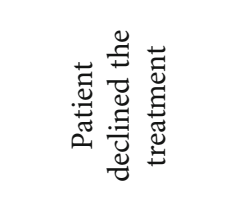 & 1 & 1 & 1 & I & 1 & 1 & 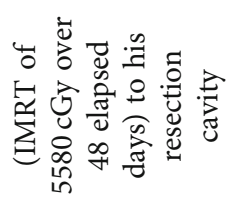 & 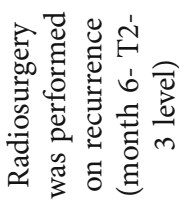 \\
\hline 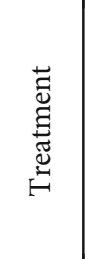 & 色 & 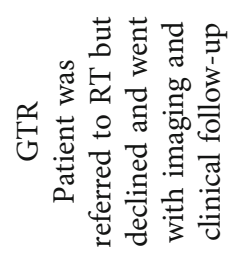 & 兹 & త্ & 号 & 获 & 号 & 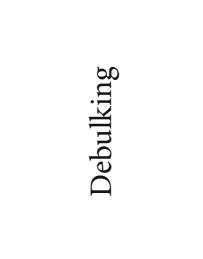 & 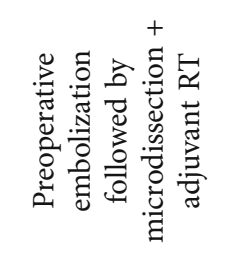 & 苞 \\
\hline 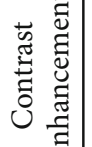 & 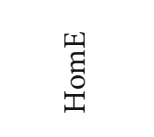 & 떰 & 더 & $\begin{array}{l}\text { 듬 } \\
\text { 폰 }\end{array}$ & I & 덜 & 딜 & 山् & 띠 & 山 \\
\hline \begin{tabular}{l}
3 \\
$\stackrel{1}{1}$ \\
\multirow{1}{*}{}
\end{tabular} & 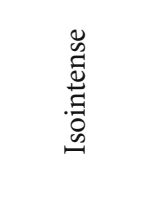 & 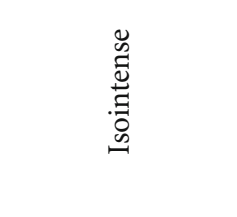 & 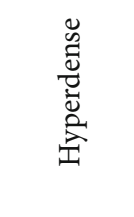 & 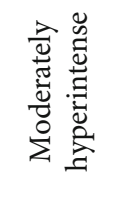 & $\tilde{z}$ & 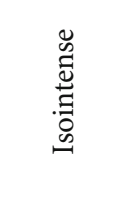 & 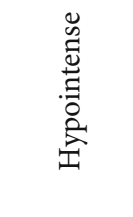 & $\tilde{z}$ & $\tilde{z}$ & $\tilde{z}$ \\
\hline $\begin{array}{l}3 \\
\frac{1}{H} \\
\end{array}$ & 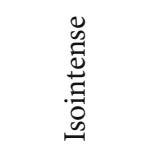 & 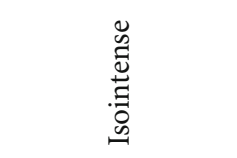 & 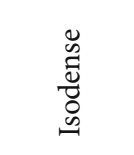 & $\tilde{z}$ & $\tilde{z}$ & 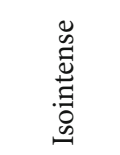 & 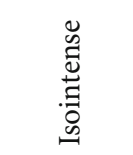 & $\tilde{z}$ & $\tilde{z}$ & $\tilde{z}$ \\
\hline 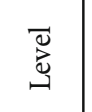 & $\stackrel{\stackrel{\sim}{F}}{\stackrel{\vec{H}}{\vec{H}}}$ & $\begin{array}{l}\stackrel{\circ}{\vec{H}} \\
\stackrel{1}{\hat{H}}\end{array}$ & $\stackrel{ }{F}$ & 3 & $\begin{array}{l}\vec{H} \\
\stackrel{m}{F}\end{array}$ & $\begin{array}{l}\hat{N} \\
\stackrel{1}{b} \\
\qquad\end{array}$ & I & $\begin{array}{l}\stackrel{7}{F} \\
\stackrel{1}{H}\end{array}$ & 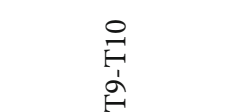 & $\begin{array}{l}3 \\
\dot{U}\end{array}$ \\
\hline 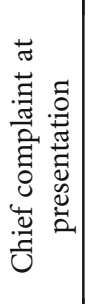 & 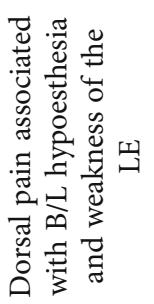 & 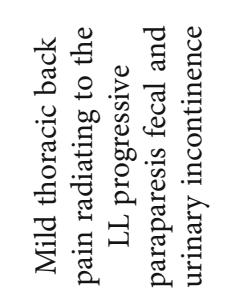 & 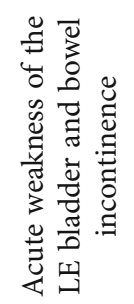 & 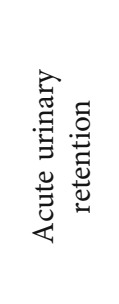 & 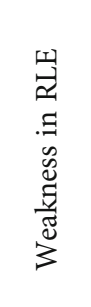 & 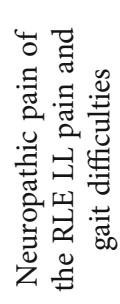 & 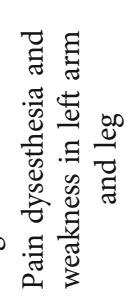 & 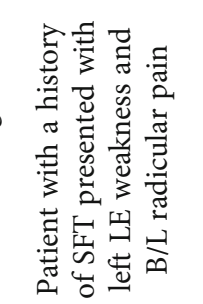 & 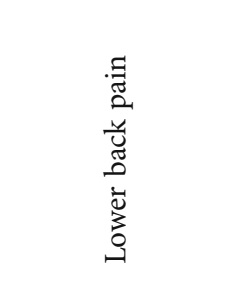 & 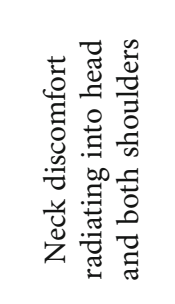 \\
\hline 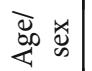 & $\bar{d} \Sigma$ & $\grave{i} \Sigma$ & $\stackrel{\infty}{i} \Sigma$ & $\bar{N} \Sigma$ & 辛 & $\grave{o} \Sigma$ & 太ิ $\Sigma$ & $\bar{\alpha} \Sigma$ & 全 $\Sigma$ & $\grave{D} \Sigma$ \\
\hline 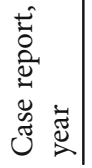 & 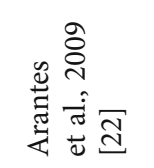 & 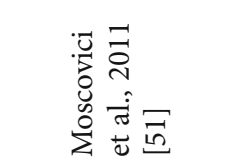 & 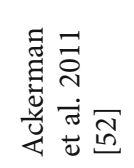 & 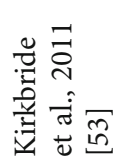 & 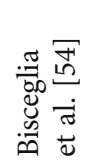 & 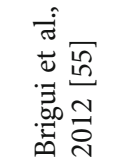 & 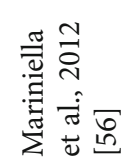 & 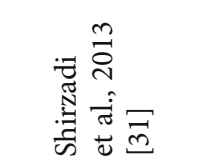 & 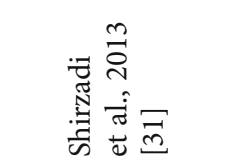 & 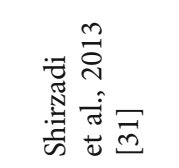 \\
\hline
\end{tabular}




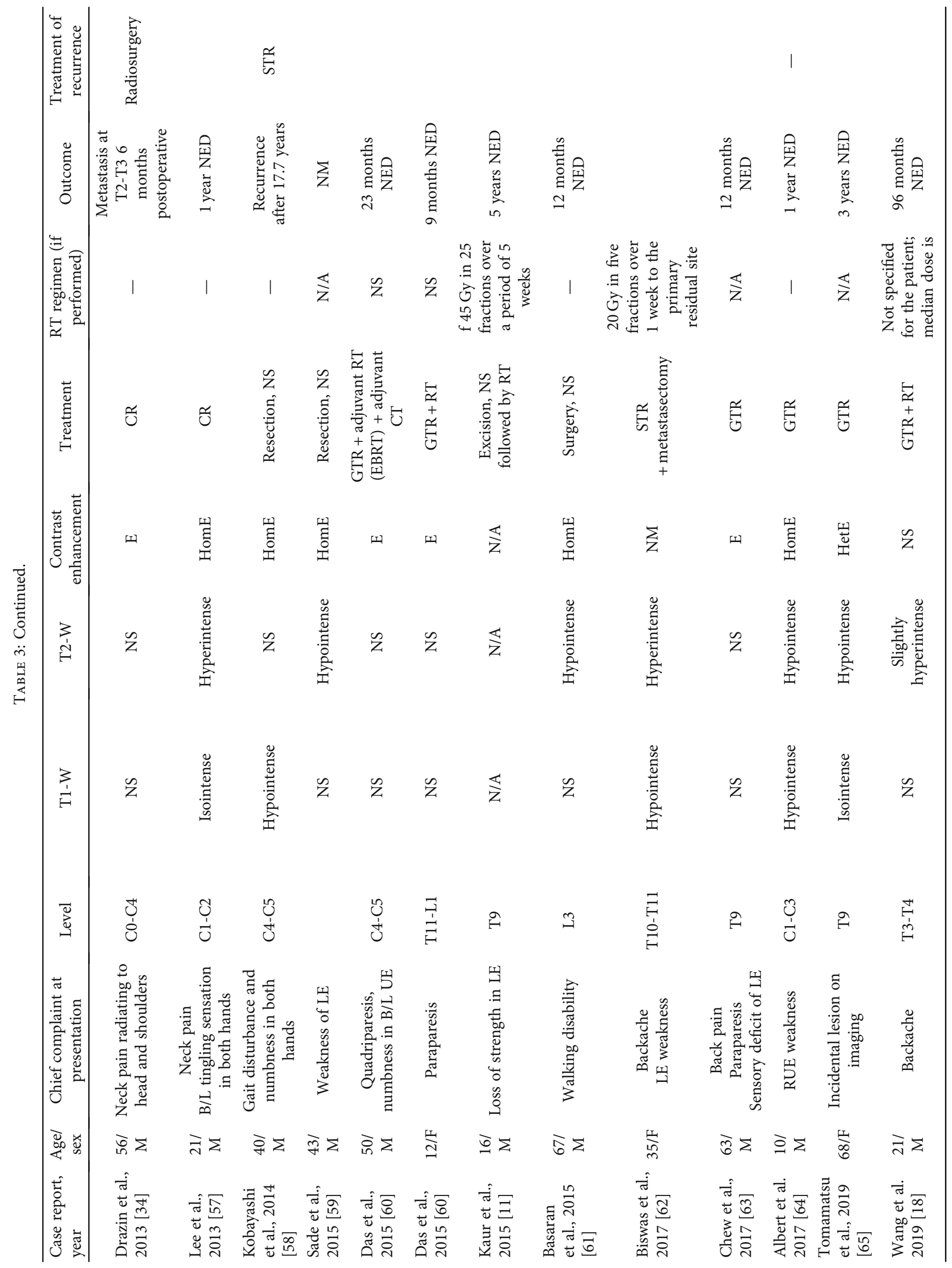




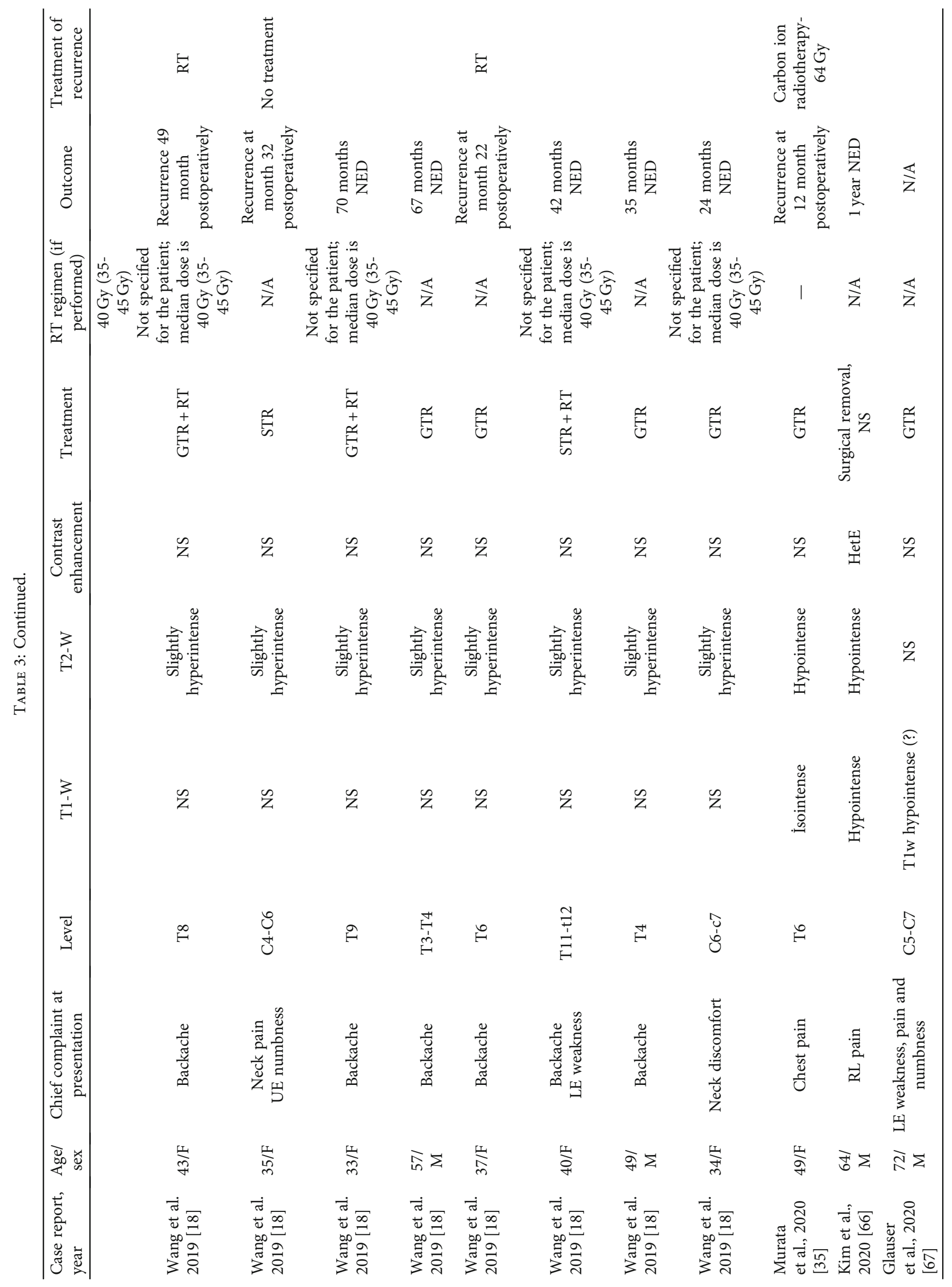




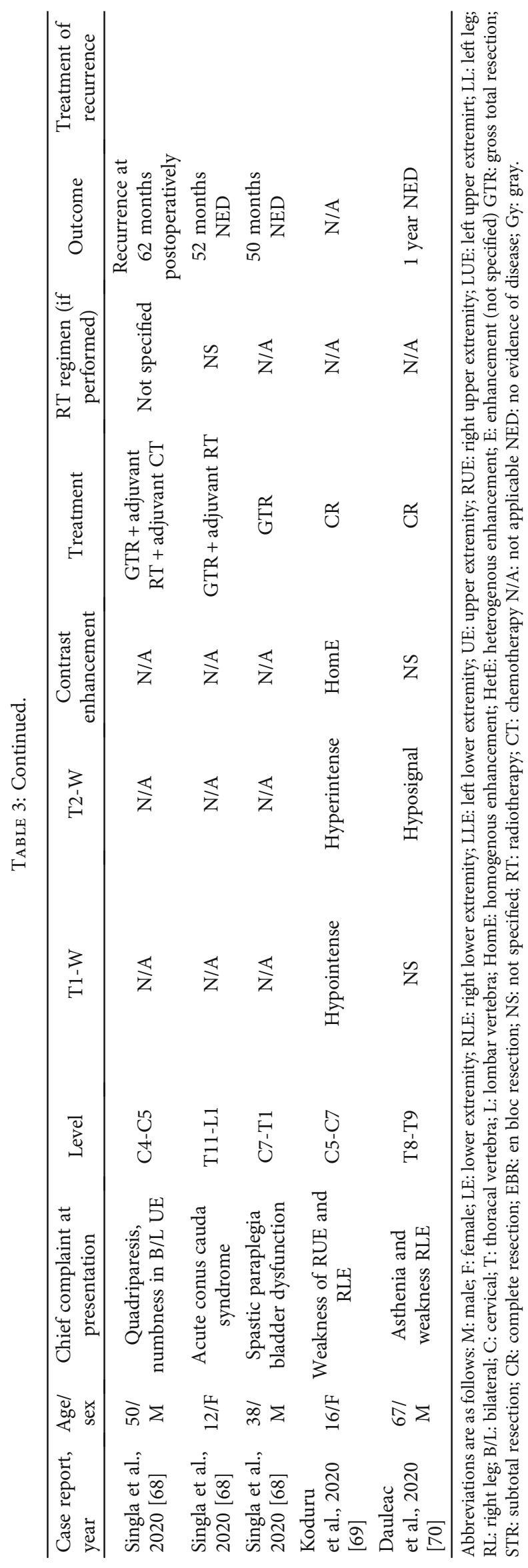




\section{Conclusion}

Spinal type IIA SFT is a rare entity with less than 50 case reports in the literature. GTR is the required treatment option while the role of adjuvant radiotherapy and its indications is yet to be discussed. We contribute to the literature by presenting a rare case in which close follow-up ensued STR, and radiotherapy was performed when the lesion recurred. We believe that the increase in the number of cases in the literature will help and contribute to the embodiment of the therapeutic algorithm of the disease in question.

\section{Conflicts of Interest}

The authors declare that they have no conflicts of interest.

\section{References}

[1] S. C. Huang and H. Y. Huang, "Solitary fibrous tumor: an evolving and unifying entity with unsettled issues," Histology and Histopathology, vol. 34, no. 4, pp. 313-334, 2019.

[2] M. Zhanlong, S. Haibin, F. Xiangshan, S. Jiacheng, and N. Yicheng, "Variable solitary fibrous tumor Locations," Medicine, vol. 95, no. 13, article e3031, 2016.

[3] C. E. Yalcin and T. Tihan, "Solitary fibrous tumor/hemangiopericytoma dichotomy Revisited," Advances in Anatomic Pathology, vol. 23, no. 2, pp. 104-111, 2016.

[4] B. Davanzo, R. E. Emerson, M. Lisy, L. G. Koniaris, and J. K. Kays, "Solitary fibrous tumor," Translational Gastroenterology and Hepatology, vol. 3, p. 94, 2018.

[5] I. Djan, B. Petrovic, M. Erak, I. Nikolic, and S. Lucic, "Radiotherapy treatment planning: benefits of CT-MR image registration and fusion in tumor volume delineation," Vojnosanitetski Pregled, vol. 70, no. 8, pp. 735-739, 2013.

[6] F. M. Kong, T. Ritter, D. J. Quint et al., "Consideration of dose limits for organs at risk of thoracic radiotherapy: atlas for lung, proximal bronchial tree, esophagus, spinal cord, ribs, and brachial plexus," International Journal of Radiation Oncology • Biology • Physics, vol. 81, no. 5, pp. 1442-1457, 2011.

[7] J. P. Kirkpatrick, A. J. van der Kogel, and T. E. Schultheiss, "Radiation dose-volume effects in the spinal cord," International Journal of Radiation Oncology • Biology • Physics, vol. 76, no. 3, 3 Supplement, pp. S42-S49, 2010.

[8] S. M. Bentzen, L. S. Constine, J. O. Deasy et al., "Quantitative Analyses of Normal Tissue Effects in the Clinic (QUANTEC): an introduction to the scientific issues," International Journal of Radiation Oncology • Biology • Physics, vol. 76, no. 3, pp. S3-S9, 2010.

[9] K. Aghayev, F. Vrionis, and M. C. Chamberlain, "Adult intradural primary spinal cord tumors," Journal of the National Comprehensive Cancer Network, vol. 9, no. 4, pp. 434-447, 2011.

[10] S. Grimm and M. C. Chamberlain, "Adult primary spinal cord tumors," Expert Review of Neurotherapeutics, vol. 9, no. 10, pp. 1487-1495, 2009.

[11] J. Kaur, S. Pandit, M. C. Sharma, P. K. Julka, and G. K. Rath, "Intradural extra medullary hemangiopericytoma of dorsal spine," Child's Nervous System, vol. 31, no. 1, pp. 173-175, 2015.
[12] K. K. Koeller and R. Y. Shih, "Intradural extramedullary spinal neoplasms: radiologic-pathologic correlation," Radiographics, vol. 39, no. 2, pp. 468-490, 2019.

[13] H. G. Liu, A. C. Yang, N. Chen, J. Yang, X. G. Qiu, and J. G. Zhang, "Hemangiopericytomas in the Spine," Neurosurgery, vol. 72, no. 1, pp. 16-24, 2013.

[14] J. W. M. van Goethem, L. van den Hauwe, Ö. Özsarlak, A. M. A. de Schepper, and P. M. Parizel, "Spinal tumors," European Journal of Radiology, vol. 50, no. 2, pp. 159-176, 2004.

[15] A. R. Keraliya, S. H. Tirumani, A. B. Shinagare, A. Zaheer, and N. H. Ramaiya, "Solitary fibrous tumors: 2016 imaging update," Radiologic Clinics of North America, vol. 54, no. 3, pp. 565-579, 2016.

[16] B. Ghanim, S. Hess, P. Bertoglio et al., "Intrathoracic solitary fibrous tumor - an international multicenter study on clinical outcome and novel circulating biomarkers," Scientific Reports, vol. 7, no. 1, p. 12557, 2017.

[17] A. Flint and S. W. Weiss, "CD-34 and keratin expression distinguishes solitary fibrous tumor (fibrous mesothelioma) of pleura from desmoplastic mesothelioma," Human Pathology, vol. 26, no. 4, pp. 428-431, 1995.

[18] J. Wang, K. Zhao, L. Han et al., "Solitary fibrous tumor/ hemangiopericytoma of spinal cord: a retrospective singlecenter study of 16 cases," World Neurosurgery, vol. 123, pp. e629-e638, 2019.

[19] L. A. Doyle, M. Vivero, C. D. M. Fletcher, F. Mertens, and J. L. Hornick, "Nuclear expression of STAT6 distinguishes solitary fibrous tumor from histologic mimics," Modern Pathology, vol. 27, no. 3, pp. 390-395, 2014.

[20] M. Vivero, L. A. Doyle, C. D. M. Fletcher, F. Mertens, and J. L. Hornick, "GRIA2 is a novel diagnostic marker for solitary fibrous tumour identified through gene expression profiling," Histopathology, vol. 65, no. 1, pp. 71-80, 2014.

[21] S. C. Huang, C. F. Li, Y. C. Kao et al., "The clinicopathological significance ofNAB2-STAT6gene fusions in 52 cases of intrathoracic solitary fibrous tumors," Cancer Medicine, vol. 5, no. 2, pp. 159-168, 2016.

[22] M. Arantes, M. Honavar, A. R. Vaz, M. Resende, and J. R. Pereira, "Tumeur fibreuse solitaire du rachis dorsal," Neurochirurgie, vol. 55, no. 6, pp. 573-575, 2009.

[23] L. A. Doyle, "Sarcoma classification: an update based on the 2013 World Health Organization Classification of Tumors of Soft Tissue and Bone," Cancer, vol. 120, no. 12, pp. 17631774, 2014.

[24] C. D. Fletcher, "The evolving classification of soft tissue tumours - an update based on the new 2013 WHO classification," Histopathology, vol. 64, no. 1, pp. 2-11, 2014.

[25] B. Kayani, A. Sharma, M. D. Sewell et al., "A review of the surgical management of extrathoracic solitary fibrous tumors," American Journal of Clinical Oncology, vol. 41, no. 7, pp. 687-694, 2018.

[26] A. J. Bishop, G. K. Zagars, E. G. Demicco, W. L. Wang, B. W. Feig, and B. A. Guadagnolo, "Soft tissue solitary fibrous Tumor," American Journal of Clinical Oncology, vol. 41, no. 1, pp. 81-85, 2018.

[27] K. Nakahara, M. Yamada, S. Shimizu, and K. Fujii, "Stereotactic radiosurgery as adjuvant treatment for residual solitary fibrous tumor," Journal of Neurosurgery, vol. 105, no. 5, pp. 775-776, 2006.

[28] Y. Zhao and J. Z. Zhao, "Clinical and pathological characteristics of primary intraspinal hemangiopericytoma and choice of 
treatment," Chinese Medical Journal, vol. 120, no. 2, pp. 115119, 2007.

[29] Y. Wang, J. Zhang, Q. Liu, F. Liu, X. Zhu, and J. Zhang, "Solitary fibrous tumor of the pineal region with delayed ectopic intracranial metastasis: a case report and review of the literature," Medicine, vol. 98, no. 21, article e15737, 2019.

[30] Q. Jia, Z. Zhou, D. Zhang et al., "Surgical management of spinal solitary fibrous tumor/hemangiopericytoma: a case series of 20 patients," European Spine Journal, vol. 27, no. 4, pp. 891-901, 2018.

[31] A. Shirzadi, D. Drazin, M. Gates et al., "Surgical management of primary spinal hemangiopericytomas: an institutional case series and review of the literature," European Spine Journal, vol. 22, Supplement 3, pp. 450-459, 2013.

[32] M. Krengli, T. Cena, T. Zilli et al., "Radiotherapy in the treatment of extracranial hemangiopericytoma/solitary fibrous tumor: study from the Rare Cancer Network," Radiotherapy and Oncology, vol. 144, pp. 114-120, 2020.

[33] E. Muñoz, A. Prat, B. Adamo, S. Peralta, S. Ramón y Cajal, and C. Valverde, "A rare case of malignant solitary fibrous tumor of the spinal cord," Spine, vol. 33, no. 12, pp. E397-E399, 2008.

[34] D. Drazin, J. P. Johnson, F. Shweikeh, and S. Bannykh, "Hemangiopericytoma invading the craniovertebral junction: first reported case and review of the literature," Journal of Neurosurgery, vol. 4, no. 1, pp. 32-34, 2013.

[35] K. Murata, K. Endo, T. Aihara et al., "Salvage carbon ion radiotherapy for recurrent solitary fibrous tumor: a case report and literature review," Journal of Orthopaedic Surgery (Hong Kong), vol. 28, no. 1, 2020.

[36] P. J. Pitlyk, M. B. Dockery, and R. H. Miller, "Hemangiopericytoma of the spinal cord: report of three cases," Neurology, vol. 15, no. 7, pp. 649-653, 1965.

[37] C. Kitanaka, M. Kuwahara, and A. Teraoka, "Intradural, purely extramedullary hemangioblastoma of the spinal cordcase report," Neurologia Medico-Chirurgica, vol. 33, no. 6, pp. 377-380, 1993.

[38] A. M. Malek, S. J. Weller, D. L. Price Jr., and J. R. Madsen, “Solitary fibrous tumor presenting as a symptomatic intraspinal mass: case report," Neurosurgery, vol. 40, no. 4, pp. 844-847, 1997.

[39] T. Kanahara, M. Hirokawa, M. Shimizu et al., "Solitary fibrous tumor of the spinal Cord," Acta Cytologica, vol. 43, no. 3, pp. 425-428, 1999.

[40] A. Brunori, S. Cerasoli, R. Donati, F. Giangaspero, and F. Chiappetta, "Solitary fibrous tumor of the meninges: two new cases and review of the literature," Surgical Neurology, vol. 51, no. 6, pp. 636-640, 1999.

[41] S. J. Vorster, R. A. Prayson, and J. H. Lee, "Solitary fibrous tumor of the thoracic spine. Case report and review of the literature," Journal of Neurosurgery, vol. 92, no. 2, pp. 217-220, 2000.

[42] O. Kurtkaya, I. Elmaci, A. Sav, and M. N. Pamir, "Spinal solitary fibrous tumor: seventh reported case and review of the literature," Spinal Cord, vol. 39, no. 1, pp. 57-60, 2001.

[43] H. Dufour, P. Métellus, S. Fuentes et al., "Meningeal hemangiopericytoma: a retrospective study of 21 patients with special review of postoperative external radiotherapy," Neurosurgery, vol. 48, no. 4, pp. 756-763, 2001.

[44] S. Betchen, A. Schwartz, C. Black, and K. Post, "Intradural hemangiopericytoma of the lumbar spine: case report," Neurosurgery, vol. 50, no. 3, pp. 654-657, 2002.
[45] S. Pizzolitto, G. Falconieri, and G. Demaglio, "Solitary fibrous tumor of the spinal cord: a clinicopathologic study of two cases," Annals of Diagnostic Pathology, vol. 8, no. 5, pp. 268275, 2004.

[46] R. J. Bohinski, E. Mendel, K. D. Aldape, and L. D. Rhines, "Intramedullary and extramedullary solitary fibrous tumor of the cervical spine," Journal of Neurosurgery, vol. 100, no. 4, pp. 358-363, 2004.

[47] S. Piana, I. Putrino, A. Cavazza, and E. Nigrisoli, "Solitary fibrous tumor of the spinal nerve rootlet: report of a case mimicking schwannoma," Archives of Pathology \& Laboratory Medicine, vol. 128, no. 3, pp. 335-337, 2004.

[48] T. Ogawa, E. Moriyama, H. Beck, and H. Sonobe, "Solitary fibrous tumor of the thoracic spinal Cord-Case Report-," Neurologia Medico-Chirurgica, vol. 45, no. 7, pp. 371-374, 2005.

[49] N. M. Pakasa, B. Pasquier, M. L. Chambonnière et al., "Atypical presentations of solitary fibrous tumors of the central nervous system: an analysis of unusual clinicopathological and outcome patterns in three new cases with a review of the literature," Virchows Archiv, vol. 447, no. 1, pp. 81-86, 2005.

[50] D. Fitzpatrick, J. Mahajan, M. Lewkowitz, K. Black, A. Setton, and R. Woldenberg, "Intradural hemangiopericytoma of the lumbar spine: a rare entity," American Journal of Neuroradiology, vol. 30, no. 1, pp. 152-154, 2009.

[51] S. Moscovici, F. Ramirez-DeNoriega, Y. Fellig, G. Rosenthal, J. E. Cohen, and E. Itshayek, "Intradural extramedullary hemangiopericytoma of the thoracic spine infiltrating a nerve Root," Spine, vol. 36, no. 23, pp. E1534-E1539, 2011.

[52] P. D. Ackerman, A. Khaldi, and J. F. Shea, "Intradural hemangiopericytoma of the thoracic spine: a case report," The Spine Journal, vol. 11, no. 7, pp. e9-e14, 2011.

[53] M. Kirkbride, K. Heitman, and A. Szallasi, "Spinal solitary fibrous tumor mimicking hemangioma," Clinical Neuropathology, vol. 30, no. 5, pp. 149-151, 2011.

[54] M. Bisceglia, L. Dimitri, G. Giannatempo et al., "Solitary fibrous tumor of the central nervous System," International Journal of Surgical Pathology, vol. 19, no. 4, pp. 476-486, 2011.

[55] M. Brigui, S. Aldea, M. Bernier, S. Bennis, E. Mireau, and S. Gaillard, "Two patients with a solitary fibrous tumor of the thoracic spinal cord," Journal of Clinical Neuroscience, vol. 20, no. 2, pp. 317-319, 2013.

[56] G. Mariniello, M. Napoli, C. Russo et al., "MRI features of spinal solitary fibrous Tumors," The Neuroradiology Journal, vol. 25, no. 5, pp. 610-616, 2012.

[57] C. H. Lee, K. J. Kim, T. A. Jahng, and H. J. Kim, "Spinal hemangiopericytoma which needed intraoperative embolization due to unexpected bleeding," Journal of Korean Neurosurgical Association, vol. 54, no. 3, pp. 253-256, 2013.

[58] K. Kobayashi, S. Imagama, Z. Ito et al., "Recurrence of solitary fibrous tumor of the cervical spinal cord," Nagoya Journal of Medical Science, vol. 76, no. 1-2, pp. 217-223, 2014.

[59] R. Sade, M. Çakır, H. Ogul, Ç. Çalıkoğlu, and M. Kantarci, "Very rare reason of spinal cord compression: solitary fibrous tumor," The Spine Journal, vol. 15, no. 5, pp. 1158-1159, 2015.

[60] A. Das, P. K. Singh, V. Suri, M. N. Sable, and B. S. Sharma, "Spinal hemangiopericytoma: an institutional experience and review of literature," European Spine Journal, vol. 24, no. S4, pp. 606-613, 2015.

[61] R. Basaran, M. Kaksi, M. Onoz, E. Balkuv, and A. Sav, "Intradural solitary fibrous tumor of the lumbar spine: a distinctive 
case report," Case Reports in Neurological Medicine, vol. 2015, Article ID 708472, 5 pages, 2015.

[62] R. Biswas, A. Halder, P. P. Ramteke, and R. Pandey, "Malignant solitary fibrous tumor of thoracic spine with distant metastases: second reported case and review of the literature," Journal of Craniovertebral Junction \& Spine, vol. 8, no. 1, pp. 79-81, 2017.

[63] L. S. Chew, X. J. Han, K. K. Tan, and M. M. Bundele, "Hemangiopericytoma of the thoracic spine: a case report," Journal of Surgical Case Reports, vol. 2017, no. 7, 2017.

[64] G. W. Albert and M. Gokden, "Solitary fibrous tumors of the spine: a pediatric case report with a comprehensive review of the literature," Journal of Neurosurgery. Pediatrics, vol. 19, no. 3, pp. 339-348, 2017.

[65] Y. Tomomatsu, Y. Iizuka, T. Mieda et al., "Intradural-extramedullary solitary fibrous tumor/hemangiopericytoma with a negative result on fluorodeoxyglucose-positron emission tomography/computed tomography," Case Reports in Orthopedics, vol. 2019, Article ID 3926903, 5 pages, 2019.

[66] B. J. Kim, E. Yoo, J. Choi, and S. Kim, "Intradural-extramedullary solitary fibrous tumor of the thoracic spine: a case report," Radiology Case Reports, vol. 15, no. 6, pp. 709-711, 2020.

[67] G. Glauser, N. Sharma, M. Kritikos, N. R. Malhotra, and O. Choudhri, "Cervical, intradural extramedullary solitary fibrous tumor of the spinal cord: a case report and review of the literature," Asian Journal of Neurosurgery, vol. 15, no. 1, pp. 204-209, 2020.

[68] R. Singla, P. K. Singh, G. Khanna et al., "An institutional review of 10 cases of spinal hemangiopericytoma/solitary fibrous tumor," Neurology India, vol. 68, no. 2, pp. 448-453, 2020.

[69] M. R. Koduru, S. Ail, J. Shetty, and V. Shetty, "Solitary fibrous tumour of cervical spinal cord," Annals of African Medicine, vol. 19, no. 2, pp. 144-146, 2020.

[70] C. Dauleac, A. Vasiljevic, and M. Berhouma, "How to differentiate spinal cord hemangiopericytoma from common spinal cord tumor?," Neurochirurgie, vol. 66, no. 1, pp. 53-55, 2020. 